\title{
Erratum to: Long-Term Durability and Rigidity of Structurally Heterogeneous Gas Turbine Engine Blades
}

\author{
A. V. Mishchenko ${ }^{a, *}$ and Yu. V. Nemirovskii ${ }^{b}$ \\ ${ }^{a}$ Novosibirsk State University of Architecture and Civil Engineering (Sibstrin), ul. Leningradskaya 113, \\ Novosibirsk, 630008 Russia \\ ${ }^{b}$ S.A. Khristianovich Institute of Theoretical and Applied Mechanics, \\ Siberian Branch of the Russian Academy of Sciences, ul. Institutskaya 4/1, Novosibirsk, 630090 Russia \\ *e-mail:mavr59@ngs.ru \\ Received November 9, 2020
}

DOI: $10.3103 / \mathrm{S} 1068799820030265$

The TeX presentation of formulas was updated in HTML file.

The original article can be found online at https://doi.org/10.3103/S1068799820020038. 